\title{
Reducing Stereotyping Through Mindfulness: Effects on Automatic Stereotype-Activated Behaviors
}

\section{Citation}

Djikic, Maja, Ellen J. Langer, and Sarah Fulton Stapleton. 2008. Reducing stereotyping through mindfulness: effects on automatic stereotype-activated behaviors. Journal of Adult Development 15, no. 2: 106-111.

\section{Published Version}

http://dx.doi.org/10.1007/s10804-008-9040-0

\section{Permanent link}

http://nrs.harvard.edu/urn-3:HUL.InstRepos:3196089

\section{Terms of Use}

This article was downloaded from Harvard University's DASH repository, and is made available under the terms and conditions applicable to Other Posted Material, as set forth at http:// nrs.harvard.edu/urn-3:HUL.InstRepos:dash.current.terms-of-use\#LAA

\section{Share Your Story}

The Harvard community has made this article openly available.

Please share how this access benefits you. Submit a story.

\section{Accessibility}




\title{
Reducing Stereotyping Through Mindfulness: Effects on Automatic Stereotype-Activated Behaviors
}

\author{
Maja Djikic · Ellen J. Langer · Sarah Fulton Stapleton
}

Published online: 28 May 2008

(C) Springer Science+Business Media, LLC 2008

\begin{abstract}
We assessed whether mindfulness (active categorization) can prevent automatic stereotype-activated behaviors related to the elderly. Eighty participants (mean age $=24.4$ ) were given a set of photographs to prime the dimension Old Age and were asked to categorize them multiple times, to see whether the effect of the prime could be reduced through increased mindfulness. Participants were randomly assigned to one of four conditions, where they were asked to categorize the photographs across (1) four self-generated categories; (2) four assigned categories; (3) a single category-Gender; or (4) a single categoryAge. Participants' walking speed (cf. Bargh et al. 1996, Experiment 2) was then measured, as they moved between the two experimental stations. The results show that greater mindfulness predicted greater walking speed, indicating a decrease in the effect of the automatic stereotype-activated behavior.
\end{abstract}

Keywords Mindfulness - Stereotypes - Prejudice · Elderly

\section{Introduction}

Finding techniques to reduce prejudice has preoccupied social psychologists for at least half of the last century (Allport 1954; Bar-Tal 1989; Festinger and Carlsmith

\footnotetext{
M. Djikic

Desautels Center for Integrative Thinking,

University of Toronto, Toronto, ON, Canada

E. J. Langer $(\bowtie) \cdot$ S. F. Stapleton

Department of Psychology, Harvard University, 1330 William

James Hall, 33 Kirkland Street, Cambridge, MA 02138, USA

e-mail: langer@wjh.harvard.edu
}

1959; McKay and Pitman 1993; Meshel and McGlynn 2004; Pettigrew 1975, 1998; Stangor 2000). What made their task necessarily difficult is the automaticity of stereotype activation (Brewer 1988; Devine 1989; Perdue and Gurtman 1990; Pratto and Bargh 1991). Not only does the mere presence of features associated with the stereotyped group act automatically to modify social perception and evaluation, but even more remarkably, priming stereotypes has a direct, automatic effect on behavior (Bargh et al. 1996; Devine 1989, Experiment 2). In an elegant study, Bargh and his colleagues (1996) have shown that individuals for whom an elderly stereotype was primed, walked more slowly (consistent with the elderly stereotype) than the control group. In addition, authors have shown that participants had no consciousness of the possible relationship between the stimulus words (in the scrambled sentence task used to prime the stereotype) and the elderly stereotype. What this means, in practice, is that what people consciously believe is often sidestepped in prejudiced behavior. The activation of the stereotype acts directly on behavior, making the interventions aimed at changing attitudes and beliefs even more limited.

In the present experiment we attempted to prevent the effect of stereotype on behavior through an alternative strategy that has been previously shown to decrease prejudice-mindfulness. Mindfulness (e.g., Langer 1978, $1989,1997,2005)$ is a state in which individuals continually make novel distinctions about objects of their attention. Langer and Imber (1980) argued that rather than decreasing the number of distinction individuals make about targeted individuals (by encouraging the view that 'we are all the same'), increasing the number of distinctions makes the relative importance of each distinction less important. In their study of sixth-graders, Langer et al. (1985) have shown that children for whom mindfulness 
was experimentally induced (through active categorization or distinction making) reacted to handicapped individuals by expressing action-plans that showed less discrimination (and avoidance) than the controls. In this article, we examine whether mindfulness may also be a candidate for reducing the automatic effects of stereotype activation on behavior.

The hypothesis tested in the present experiment was that an increase in mindfulness, operationalized as active categorization across a multiplicity of dimensions, will lead to a decrease in the automatic activation of behaviors related to stereotypes of elderly adults, as measured by an increased walking speed.

\section{Method}

\section{Participants}

Eighty individuals (36 females and 44 males, mean age $=24.4$ ) participated in the research. Participants were recruited from the Beacon Street Laundromat and the South Station in Boston, MA.

\section{Procedure}

Participants were informed that they would take part in a psychology study concerning person perception. They were directed to a designated table where the experimenter's desk was set up. The first experimenter had the participants read the consent form. Participants were then randomly assigned to one of the four experimental groups and given a set of 48 photographs to sort, a set that included both old (more than 65 years of age) and young (less than 30 years of age) individuals, ${ }^{1}$ thus priming the dimension of Old Age for all participants. This priming procedure was adopted to improve ecological validity (since encountering both young and the old is the manner in which most young people encounter the elderly in everyday life) and to avoid the problem of negative mood induction and its potential effect on walking speed (as addressed in Bargh et al.'s 1996, Experiment 2), by presenting participants with the same stimuli across conditions.

A pilot study revealed that $100 \%$ of 20 young individuals ( $<30$ years of age) who were presented with a set of 48 photographs containing equal numbers of young

\footnotetext{
${ }^{1}$ The pictures were provided with courtesy of Tom Jordan and Allison Madison at www.picturarts.com. Photographs were chosen to provide a representation of different ethnicities and both genders. The only large distinction among the 48 photographs shown to each participant was that each person depicted was either young (under 30 years of age) or old (above 65 years of age)
}

( $<30$ years) and old ( $>60$ years) people, and asked to indicate the most salient dimension that differentiated them, indicated age. In addition, when faced with a forced choice question of whether there were more young or old people in the sample, they overestimated the relative proportion of the elderly. When photographs of both young and old people are shown to young people, therefore, the primed dimension is Old Age, rather than just Age.

The sorting instructions for participants differed depending on the condition to which they were assigned (as described below), but the baseline prime of stereotype of Old Age was present in all conditions.

After sorting the pictures, participants were told by the first experimenter that the next part of the study would take place with another experimenter. The participant was told that it would be very helpful if they would simply walk to the second experimenter (located at a different experimental station) in order to fill out a few questionnaires thereby finishing up the study. Participants were unaware that a third experimenter was observing the walk and timing it. The third experimenter was blind to the condition of each participant and began timing when the participant started walking and stopped when he or she reached a specified point near the second experimenter where they were instructed to fill out a questionnaire package.

\section{Conditions}

Participants were randomly assigned to one of the four experimental conditions ( $N=20$ for each condition), in a decreasing order of mindfulness. To induce mindfulness in conditions 1 and 2, participants sorted photographs of people four times across four different dimensions. In conditions 3 and 4, participants sorted photographs four times across only one dimension.

\section{Condition 1: High Mindfulness (Sorting by Four Self-Generated Categories)}

Participants were told that they would sort the picture set four separate times and would need to generate a new category each time. To ensure that they were actively engaging with the pictures, they were first asked to sort using two psychological dimensions (e.g., they could choose intelligence, warmth), while the last two times they sorted, they were allowed to use any dimensions they wished (e.g., beauty, aggression). Since psychological dimensions in this context are more novel, they were expected to provoke greater mindfulness.

The first time they sorted, participants divided the pictures into two piles. For the second sorting, the participants were instructed to take one pile and sort photographs in it according to the second dimension, then take the other pile 
and do the same. Participants would, therefore, end up with four piles. Then, before sorting by the third dimension, the participants were instructed to recombine all the photographs and follow the same steps again. This was done so that there would be a visual aid to the mental concept of placing people in various categories, which allowed participants to notice that the same person can be in different categories at different times. This condition was considered to be the most mindful as it combined participants active sorting of photographs into different categories, and their ability to generate these categories as well.

\section{Condition 2: Moderate Mindfulness (Sorting by Four Assigned Categories)}

The participants were given the same set of pictures of old and young people but asked to sort using categories that had been generated in advance. The dimensions were: age, gender, attractive versus not attractive, and white versus non-white. Participants were to follow the identical procedure of sorting as in Condition 1, excluding the element of choosing one's categories [and sorting according to different kinds of categories (psychological versus physical)], while keeping the multi-dimensionality of sorting. This condition enabled us to see whether or not choosing the categories for sorting was necessary or whether enough mindfulness was generated by simply engaging in novel sorting.

\section{Condition 3: Low Mindfulness (Sorting by a Single Assigned Category-Gender)}

Participants in this condition were instructed to sort the photographs solely on the dimension of gender. Instead of being given all the pictures at once, they were given four (randomly mixed) sets of 12 photographs. This was done so that they would still sort four times. This condition was not expected to increase mindfulness, however, since they were not asked to notice new things or generate new categories about the individuals in the photographs. This condition was introduced to check whether mindlessly categorizing across just one stereotypic dimension (other than age) would be sufficient to prevent the stereotypeactivated behavior due to the old age stereotype. It was hypothesized that it would not be sufficient.

\section{Condition 4: Low Mindfulness (Sorting by a Single Assigned Category-Age)}

As in Condition 3, the participants were asked to sort four sets of pictures instead of one larger set. Rather than using gender, they were directed to sort according to the stereotypic dimension of age, strengthening the stereotype was induced by the photographs themselves.

\section{Dependent Measure}

Walking Speed was recorded as a velocity (feet per second). This measure was adapted from the research of Bargh et al. (1996, Experiment 2), who primed their participants with the elderly stereotype through scrambled sentence task, and found that participants from whom old age had been primed walked more slowly than those in the control condition. In the present experiment we attempted to prevent this stereotype-activated behavior through increased mindfulness.

\section{Questionnaire Measures}

While Walking Speed (automatic behavior activated by the Old Age stereotype) was our primary dependent variable, we introduced two additional questionnaire measures of ageism to check whether our experimental manipulation would result in a decrease in reported prejudice against the elderly, and whether a change in stereotypic behaviors depended on changes in one's stereotypic beliefs. Also included was Langer's Mindfulness Scale (LMS), to see how trait mindfulness relates to the dependent variables. As previously mentioned, these questionnaires were given when the participants arrived at the second experimental stations-after their walking speed was already measured.

The Fraboni Scale of Ageism (FSA) developed by Fraboni et al. (1990) was used to assess ageism. This is a 29-item questionnaire which produces a score positively correlated with the level of ageism. Participants rated items such as 'Many old people live in the past.' on a 4-point Likert scale ( $1=$ strongly disagree, $4=$ strongly agree). Higher scores indicated greater ageism.

The Perceived Age Competence Questionnaire (PACQ) was created as an additional measure of ageism specifically for this study based on Thornton's (2002) four basic premises of the current myths of aging. Old individuals were seen as having failed memory and being senile, sad, depressed and grouchy, lacking vitality, being set in ways, unable to learn, and unproductive. From these basic assumptions, a questionnaire was created which asked participants to rate four statements on a 4-point Likert scale $(1=$ strongly disagree, $4=$ strongly agree $)$ while looking at a picture of an old woman. The statements were: (1) This person would be good at completing a jigsaw puzzle; (2) This person is likely to remember my name after meeting me once; (3) I would like to engage in a conversation with this individual; and (4) I would be able to teach this person something new. Higher scores indicate less prejudice against the elderly. 
Langer Mindfulness Scale (LMS) (T. E. Bodner and E. L. Langer, 2001, Unpublished manuscript) measured participants' trait mindfulness. It asked participants to rate the level to which they agreed or disagree with statements pertaining to their own ability to be open to new ideas, make new distinctions, and take on different perspectives. Participants responded to items such as 'I generate few novel ideas.'(reverse-scored) on a 7-point Likert scale $(1=$ strongly disagree, $7=$ strongly agree $)$. Higher scores indicate higher trait mindfulness.

\section{Results}

Table 1 lists all the measures with their means and standard deviations, as well as correlations among them.

As predicted by past research on the impact of mindfulness on prejudice, the Langer Mindfulness Scale correlated negatively with the Fraboni Ageism Scale $(r=-.36, p<.01)$ and positively with Perceived Age Competence Scale $(r=.25, p<.05)$. Trait mindfulness was therefore correlated with reduced ageism and increased perceived competence of the elderly.

The main hypothesis was that the greater the amount of active categorization that the participant engages in (i.e., the greater their mindfulness), the less likely the automatically activated stereotype behavior (slowed walking) would be, thus leading to faster walking speed. This hypothesis was tested by a planned contrast analysis with weights of 2 (high mindfulness), 1 (moderate mindfulness), -1 (low mindfulness) and -2 (low mindfulness), according to which the Gender condition is marginally more mindful than Age (making the contrast more conservative than our hypothesis). The contrast was significant for Walking Speed, $F(1,78)=3.97, p=.05$.

The descriptive statistics for each condition are presented in Table 2.

Experimental condition did not affect the questionnaire measures of ageism, FSA or PACQ.

A post-hoc analysis showed there were no significant differences in Walking Speed between Conditions 1 and 2, nor between Conditions 3 and 4, indicating that it is the

Table 1 Means, standard deviations, and correlations among all the measures

\begin{tabular}{|c|c|c|c|c|c|}
\hline Measure & $\mathrm{M}(\mathrm{SD})$ & 1. & 2. & 3. & 4 \\
\hline 1. Walking Speed (ft./sec.) & $3.44(1.14)$ & 1.00 & & & \\
\hline 2. Fraboni Scale of Ageism & $16.50(9.65)$ & .09 & 1.00 & & \\
\hline 3. Perceived Age Competence Questionnaire & $12.31(1.69)$ & -.01 & $-.48 * *$ & 1.00 & \\
\hline 4. Langer Mindfulness Scale & $59.50(12.05)$ & -.15 & $-.36 * *$ & $.25 *$ & 1.00 \\
\hline
\end{tabular}

* (Correlation is significant at .05 level, two-tailed)

** (Correlation is significant at .01 level, two-tailed)

Table 2 Means and standard deviations for each condition

\begin{tabular}{|c|c|c|c|c|}
\hline \multirow[t]{2}{*}{ Sorting according to: } & \multicolumn{4}{|l|}{ Condition } \\
\hline & $\begin{array}{l}1 \\
4 \text { self-generated } \\
\text { categories }\end{array}$ & $\begin{array}{l}2 \\
4 \text { assigned } \\
\text { categories }\end{array}$ & $\begin{array}{l}3 \\
1 \text { assigned } \\
\text { category: Gender }\end{array}$ & $\begin{array}{l}4 \\
1 \text { assigned } \\
\text { category: Age }\end{array}$ \\
\hline \multicolumn{5}{|l|}{ Walking speed (ft./sec.) } \\
\hline Mean & 3.92 & 3.89 & 3.38 & 2.99 \\
\hline $\mathrm{SD}$ & $(.98)$ & $(1.55)$ & $(1.13)$ & $(1.01)$ \\
\hline \multicolumn{5}{|l|}{ Fraboni scale of ageism } \\
\hline Mean & 15.2 & 15.7 & 19.3 & 15.28 \\
\hline SD & $(8.73)$ & $(10.46)$ & (10.19) & $(9.48)$ \\
\hline \multicolumn{5}{|c|}{ Perceived age competence e } \\
\hline Mean & 12.8 & 12.35 & 11.63 & 12.33 \\
\hline SD & $(1.32)$ & $(1.81)$ & $(1.6)$ & $(1.64)$ \\
\hline \multicolumn{5}{|c|}{ Langer mindfulness scale } \\
\hline Mean & 59.3 & 61.73 & 57.63 & 64.13 \\
\hline SD & (14.75) & (10.25) & (10.36) & (11.49) \\
\hline
\end{tabular}


number of novel categorizations, rather than their source (self-generated or not) or their content (Age versus Gender) that has the greatest impact on preventing the automatic effects of stereotype activation on behavior.

\section{Discussion}

As hypothesized, when mindfulness (active categorization) is experimentally induced, it can prevent automatic stereotype-activated behavior. Increasingly greater active delineation of categories reduced the automatic stereotypeactivated effect, thus leading to greater Walking Speed. However, the negative correlations between trait mindfulness (as measured by Langer Mindfulness Scale) and Fraboni Ageism Scale, and positive correlation with Perceived Age Competence Questionnaire, seem to suggest that these behaviors may, in time, result in belief change as well. The very individuals who habitually engage in active distinction-making are the those who also report less discrimination against the elderly.

While Bargh et al.'s (1996) conclusions about automatic stereotype activation on behavior seemed rather discouraging for those interested in reducing prejudice (given that one can be led to exhibit stereotyped behavior without 'consulting' their belief system, thus maintaining the cycle of stereotyping), the present results offer new hope. Increasing mindfulness can act directly on behavior as well, thus potentially providing a natural interruption in the cycle of stereotyped behavior.

The effect of mindfulness (active categorization) on automatic stereotypic effects is unlikely to be the result of another strategy for reducing the effects of stereotypes, unpriming (Sparrow and Wegner 2006). Unpriming is a decrease in the influence of the primed knowledge following a behavior that expresses that knowledge. The effect of mindfulness in this context is more likely due to the dilution of the original elderly prime through the activation of other stereotypes (gender, race, intelligence, etc.). This potential explanation falls in line with the results of Cesario et al. (2006), who show that automatic social behavior has a motivational component, and that it may result from perceivers preparing to interact with stereotyped group members. For example, walking slowly can be considered a reasonable preparatory action if one is about to take a walk with an elderly person. Viewed from the perspective of Cesario et al. (2006), our increase in active categorizations requires a more complex preparatory action since one is about to interact with a multiplicity of stereotype targets (for example, a non-white, athletic, and intelligent elderly woman), thus resulting in a different behavior from what would be deemed appropriate if one is about to interact with someone categorized simply as an 'elderly' person.
The experiment presented here suggests that the automatized cycle of prejudice-whereby individuals unconsciously exhibit stereotype-activated behaviors often inducing, in turn, more stereotypic behaviors from the target members-can be interrupted.

\section{References}

Allport, G. W. (1954). The nature of prejudice. Reading, MA: Addison-Wesley.

Bargh, J. A., Chen, M., \& Burrows, L. (1996). Automaticity of social behavior: Direct effects of trait construct and stereotype activation on action. Journal of Personality and Social Psychology, 71(2), 230-244.

Bar-Tal, Y. (1989). Can leaders change followers' stereotypes? In D. Bar-Tal, C. F. Grauman, A. W. Kruglanski, \& W. Stroebe (Eds.), Stereotyping and prejudice: Changing conceptions (pp. 225242). New York: Springer-Verlag.

Brewer, M. B. (1988). A dual process model of impression formation. In T. K. Srull \& R. S. Wyer Jr (Eds.), Advances in social cognition (Vol. 1, pp. 1-36). Hillside, NJ: Erlbaum.

Cesario, J., Plaks, J. E., \& Higgins, E. T. (2006). Automatic social behavior as motivated preparation to interact. Journal of Personality and Social Psychology, 90(6), 892-910.

Devine, P. G. (1989). Stereotypes and prejudice: Their automatic and controlled components. Journal of Social and Personality Psychology, 39, 360-367.

Festinger, L., \& Carlsmith, J. M. (1959). Cognitive consequences of forced compliance. Journal of Abnormal and Social Psychology, $58,202-210$.

Fraboni, M., Saltstone, R., \& Hughes, S. (1990). The Fraboni scale of ageism: An attempt at a more precise measure of ageism. Canadian Journal on Aging, 9(1), 56-66.

Langer, E. J. (1978). Rethinking the role of thought in social interaction. In J. Harvey, W. Ickes, \& R. Kiss (Eds.), New directions in attribution research (Vol. 2, pp. 35-58). New Jersey: Lawrence Erlbaum Associates.

Langer, E. J. (1989). Mindfulness. Cambridge, MA: Perseus Books Group.

Langer, E. J. (1997). The power of mindful learning. Reading: Addison-Wesley.

Langer, E. J. (2005). On becoming an artist: Reinventing yourself through mindful creativity. New York: Ballantine Books.

Langer, E. J., Bashner, R., \& Chanowitz, B. (1985). Decreasing prejudice by increasing discrimination. Journal of Personality and Social Psychology, 49, 113-120.

Langer, E. J., \& Imber, L. (1980). The role of mindlessness in the perception of deviance. Journal of Personality and Social Psychology, 39, 360-367.

McKay, S., \& Pitman, J. (1993). Determinants of Anglo-Australian stereotypes of the Vietnamese in Australia. Australian Journal of Psychology, 45, 17-23.

Meshel, D. S., \& McGlynn, R. P. (2004). Intergenerational contact, attitudes, and stereotypes of adolescents and older people. Educational Gerontology, 30, 457-479.

Perdue, C. W., \& Gurtman, M. B. (1990). Evidence for the automaticity of ageism. Journal of Experimental Social Psychology, 26, 199-216.

Pettigrew, T. F. (1975). The racial integration of the schools. In T. F. Pettigrew (Ed.), Racial discrimination in the United States (pp. 224-239). New York: Harper \& Row.

Pettigrew, T. F. (1998). Intergroup contact theory. Annual Review of Psychology, 49, 65-85. 
Pratto, F., \& Bargh, J. A. (1991). Stereotyping based on apparently individuating information: Trait and global components of sex stereotypes under attention overload. Journal of Experimental Social Psychology, 27, 26-47.

Sparrow, B., \& Wegner, D. M. (2006). Unpriming: The deactivation of thoughts through expression. Journal of Personality and Social Psychology, 91(6), 1009-1019.
Stangor, C. (Ed.). (2000). Stereotypes and prejudice: Essential readings (pp. 1-48). Ann Arbor, MI: Taylor \& Francis Group. Thornton, J. E. (2002). Myths of aging or ageist stereotypes. Educational Gerontology, 28, 301-312. 